\title{
$\bigcirc$ INVESTIGATING THE EFFECT OF CONTEXTUAL CLUES ON THE PROCESSING OF UNFAMILIAR WORDS IN SECOND LANGUAGE LISTENING COMPREHENSION
}

\author{
Wei Cai, University of Calgary \\ Wei Cai is an assistant professor at the University of Calgary, Canada. She special- \\ ises in second language acquisition. Her current research focuses on second language \\ listening, vocabulary acquisition, learner strategies, materials evaluation and pro- \\ duction. \\ Correspondence to Wei Cai: wcai@ucalgary.ca \\ Benny P. H. Lee, National Institute of Education \\ Benny Lee is a lecturer at the National Institute of Education, Nanyang Technolo- \\ gical University, Singapore. His research interest is in language processing and lin- \\ guistic pragmatics. \\ Correspondence to Benny P. H. Lee: benny.lee@nie.edu.sg
}

\begin{abstract}
This study examines the effect of contextual clues on the use of strategies (inferencing and ignoring) and knowledge sources (semantics, morphology, world knowledge, and others) for processing unfamiliar words in listening comprehension. Three types of words were investigated: words with local co-text clues, global co-text clues and extra-textual clues. Data were collected from 20 participants using the procedures of immediate retrospection without recall support and of stimulated recall. The results indicate that contextual clues are an important factor in learners' treatment of unfamiliar words in listening comprehension. Contrary to what some theories of inference generation predict, this study reveals that learners use the inferencing strategy more frequently for words with global co-text clues and words with extratextual clues than for words with local co-text clues. In terms of the use of knowledge sources for inferring word meaning, the learners in this study use the knowledge sources in accordance with the different types of contextual clues.
\end{abstract}

A number of researchers acknowledge that inferring the meaning of unfamiliar words is an important subskill of listening comprehension (Aitken, 1978, as cited in Buck, 2001; Richards, 1983; O’Malley, Chamot and Kupper, 1989; O’Malley and Chamot, 1990; Oxford, 1990; Field, 1998; Nation, 2001). However, most studies on strategies for processing unfamiliar words have been conducted in the field of reading comprehension; not much is known about how L2 learners process unfamiliar words in listening comprehension. This paper investigates the use of strategies for processing unfamiliar words in 
listening comprehension. In particular, it focuses on the effect of contextual clues on the processing of unfamiliar words in listening comprehension.

\section{INTRODUCTION}

An oral text exists at a particular point in time and easily fades away. This means that '[t] he listener has limited control over speech rate' (Danks and End, 1987, p. 273) and cannot refer back to the texts if in doubt (Danks and End, 1987; Buck, 2001; Field, 2003). This feature has three important implications for word comprehension in listening. Firstly, considering that what is retained by the listener is the encoded information in memory (Danks and End, 1987), words which leave more traces in memory (such as heavily repeated words or words holding prominent positions in a text) may be more easily understood than those leaving fewer traces in memory in listening comprehension. Secondly, '[1]isteners must focus more intently on understanding the central themes of discourse because the input fades quickly' (Danks and End, 1987, p. 285). This implies that words which contribute to the understanding of the theme of texts in a listening task are more likely to be understood than words describing factual details in the same listening task. Thirdly, the transient nature of listening may tax the limited capacity of working memory more heavily. This suggests that words consuming less resource in the working memory may be more easily understood. The above are some tentative speculations on the nature of word comprehension in listening. They will be discussed again later in relation to the findings of the current study.

The current study investigates the use of ignoring and inferencing strategies for processing unfamiliar words in listening comprehension. The ignoring strategy is used when learners 'notice' (Schmidt, 1990) the unfamiliar words but do not engage in 'effortful processing' (Tomlin and Villa, 1994, p. 187) to infer the word meaning. By 'noticing', we adopt Schmidt's notion (1990). According to Schmidt (1990, p. 130), noticing refers to 'focal awareness' with which 'stimuli are subjectively experienced'; it can be operationally defined as 'availability for verbal report' if the report is gathered 'concurrently or immediately following the experience' and if the experience is not 'inherently difficult to describe'.

While little attention in L2 research has been placed on the lexical ignoring strategy, much more has been written on the lexical inferencing strategy where 'informed guesses' of word meaning are made in the light of all available cues (Haastrup, 1991, p. 40). However, the use of the lexical inferencing strategy is mostly examined in reading comprehension. Given the paucity of this line of research in listening comprehension, relevant 
studies in reading comprehension are also reviewed. It should be noted that given the distinct differences between reading and listening, findings of unfamiliar word processing across the two modalities may not be comparable.

A number of researchers acknowledge that the nature of the text in which unfamiliar words are embedded is an important factor influencing word inferencing (e.g. Li, 1988; Huckin and Bloch, 1993; de Bot, Paribakht and Wesche, 1997; Paribakht and Wesche, 1999; Rieder, 2003). For instance, Li (1988, p. 402) argues that 'contextual cues can affect the process and outcome of word inference'. Some studies show that learners use different types of contextual clues to a different extent. For instance, Huckin and Bloch (1993, p. 161) identified three general types of contextual clues for lexical inferencing in reading comprehension: local linguistic constituents (e.g. 'syntactic or semantic collocations'), global text representations ('text schemas' and 'permanent memory') and world knowledge. They found that the most frequently used and effective clue was the local linguistic constituent (especially a collocating clue-word), although learners would use different clues in combination. In another study, Haynes (1993) used two types of novel target words to investigate learners' word inferencing behaviour in reading comprehension: words with local co-text clues (words whose meanings could be inferred by using the immediate sentence context) and words with global co-text clues (words whose meanings could be inferred by integrating information throughout the text). Haynes (1993) found that learners were quite successful in inferring the meaning of words with local co-text clues, but less successful in inferring the meaning of words with global co-text clues.

Nassaji (2003, pp. 655-656) found that the most frequently used knowledge source for lexical inferencing in reading comprehension is world knowledge and that one of the least used knowledge sources is discourse knowledge ('knowledge about the relation between or within sentences and the devices that make connections between the different parts of the text'). This result suggests that clues residing in one's background knowledge are more convenient to use than information residing within the text beyond the sentence level. In another study, Kaivanpanah and Alavi (2008) examined the role of linguistic knowledge in lexical inferencing and found that learners used both sentence level cues (including grammatical and semantic cues) and wider co-text beyond sentence level to infer word meaning in reading. Hamada (2009) studied English learners' word inferencing performance in reading for four weeks and observed that their strategy use exhibited a shift from local strategies (word level) to more global strategies (sentence or contextual level strategies).

Few empirical studies have specifically investigated unfamiliar word processing in listening comprehension. Nonetheless, studies which have explored listening strategies 
in general (O’Malley, Chamot and Kupper, 1989; Rost and Ross, 1991; Goh, 1997, 1998, 2002; Vandergrift, 1996, 1997, 2003) shed some light on this issue. For instance, Rost and Ross (1991) investigated learners' use of strategies for asking clarification questions in interactive listening and found that L2 learners were able to identify unfamiliar words in listening comprehension and ask clarification questions concerning the word meaning. In another study, Vandergrift (1997) investigated the strategies that learners of French used in listening comprehension. In terms of the inferencing strategy, he found that novice learners recognised a very limited number of words in listening and hence engaged in inferencing to compensate for the deficiency by using such clues as cognate words, contextual clues and extralinguistic clues (including background noise, tone of voice, and so on). In a more recent study, Vandergrift (2003, p. 495) investigated again the applications of listening strategies by French learners. He found that learners used four types of inferencing, including linguistic ('known words'), vocal ('tone of voice and/or paralinguistics'), extra-linguistic ('background sounds and relationships between speakers in an oral text, material in the response sheet, or concrete situational referents'), and between-parts inferencing ('information beyond the local sentential level').

Two observations can be made from previous studies on listening comprehension strategies in general. First, learners are able to identify unknown words in continuous speech and use the inferencing strategy to handle some unknown words. Secondly, learners use different types of clues or knowledge sources to infer word meaning to various extents. However, so far there is no study investigating how contextual clues affect learners' choice of strategies and knowledge sources for processing unfamiliar words in listening comprehension. Studies on unfamiliar word processing in reading comprehension show that contextual clues affect unfamiliar word processing. The generalizability of their findings to the listening modality is unclear. The current study was therefore conducted to investigate the effect of contextual clues on unfamiliar word processing in listening comprehension.

\section{INFERENCE GENERATION}

van den Broek (1994, pp. 561-577) proposed a general model of inference generation, particularly for causal inferences in narrative texts. His model distinguishes between three types of inferences in terms of the sources for generating inferences: connecting inferences, reinstatements and elaborative inferences (van den Broek, 1994, pp. 561-564). A connecting inference is generated by relating the statement in focus to the statement which is still activated in short term memory (STM), i.e., when they co-occur in STM. 
This tends to happen when the two statements are adjacent in the text. Because such an inference is made based on information that is already in STM, no additional processes are required. In contrast, a reinstatement is made by reactivating information from prior text that is not currently activated in STM. This means that a reinstatement occurs when the inference is generated by retrieving information not from STM but from long term memory (LTM). An elaborative inference takes place when background knowledge is used to generate the inference.

The distinction between van den Broek's connecting inferences and reinstatements echoes McKoon and Ratcliff's (1992) distinction between inferences for establishing local coherence and global coherence. Both van den Broek (1994) and McKoon and Ratcliff (1992) agree that producing inferences depending on information widely separated in the text is more demanding than producing inferences depending on immediately available information. A similar view is also expressed by Graesser, Singer and Trabasso (1994).

According to van den Broek, elaborative inferences, which are generated through activating one's background knowledge, should be more difficult than connecting inferences which depend on immediately preceding information. This is because elaborative inferences involve the additional process of accessing relevant background knowledge. However, Graesser, Singer and Trabasso (1994, p. 374) argue that when background knowledge is very familiar, it is 'activated in working memory ... at very little cost'. In such a case, it is expected that elaborative inferences can be generated with no more difficulty than connecting inferences.

The above-mentioned theories posit how comprehenders generate inferences for implicit textual information, such as the implied causal relationship between two events in narrative texts. This paper attempts to explore the applicability of these theories to the processing of unfamiliar words in listening comprehension.

\section{AIMS AND RESEARCH QUESTIONS}

Specifically, this study focuses on the lexical inferencing strategy and lexical ignoring strategy. For completeness of account, we also consider the instance of 'no attention', where learners fail to notice the unfamiliar words. The research questions addressed in this study are as follows:

1. What strategies do L2 listeners use to process unfamiliar words in different conditions, as determined by contextual clues? 
In view of van den Broek's (1994) distinction of the three types of inferences, three conditions are established in terms of contextual clues:

- Condition 1: words with local co-text clues

- Condition 2: words with global co-text clues

- Condition 3: words with extra-textual clues

2. What knowledge sources do L2 listeners use to infer word meaning in different conditions, as determined by contextual clues?

\section{METHODOLOGY}

\section{PARTICIPANTS}

Twenty students from a university in Beijing participated in this experiment. They are second-year English majors. Their ages range from 18 to 22. In China, formal English learning starts in junior high school. At the time of data collection, they have already been studying English for approximately eight years. Most of the courses that English major students take at university level are English skill courses, such as intensive reading, extensive reading, grammar, speaking and writing. In addition to these English courses, other compulsory courses include physical education, political science and Chinese. We classified the subjects' proficiency levels according to the composite score of eight listening tests administered by the English as a Second Language (ESL) program and by the instructor's assessment of the subjects' listening abilities. Among the twenty students who participated in the study, ten students have the highest mean scores of the eight listening tests and are placed in the high-proficiency group by their instructor. The other ten students have the lowest mean scores of the eight listening tests and are placed in the low-proficiency group by their instructor.

\section{LISTENING MATERIALS}

The listening materials consisted of nine texts based on popular science and mostly selected from New Scientist (see Appendix 1 for sample texts). We used originally written texts in this study for the reasons that (1) a lot of spoken texts we hear are in fact originally scripted, such as speech and news broadcasts; and (2) it is not unusual for researchers (Shohamy and Inbar, 1991; Tsui and Fullilove, 1998) to use prewritten texts as listening materials. 
Each text comprised four to five sentences and was approximately eighty words. Some modifications were made. One modification relates to the use of low-frequency words to replace high-frequency ones. To confirm the quality of the language after revision, two native speakers of American English were asked to edit the language of the revised texts when necessary. A native speaker of American English provided the recording, with an average spoken word rate of 140 words per minute. This rate is the same as the average speech rate of lectures delivered by native speakers to non-native speakers of English, as reported in Tauroza and Allison (1990).

Each text contained one word to be inferred. To ensure that no subject had previous knowledge of the target words, we used novel words in place of the original words. These novel words retained the morphological features of the original words, whether inflectional or derivational. For instance, in one text, the target novel word 'broamed' retains the inflectional ending '-ed' of the original word 'covered'; in another text, the novel word 'sloration' replaces 'extinction', retaining the derivational suffix '-ion'. Using novel words is the most efficient and secure way to ensure that subjects do not know the target words, which is vital for the current study. L2 listeners whose listening proficiency is not well developed may not be able to distinguish between unfamiliar actual words and novel words. This is especially so when the novel words are possible English words, retaining real morphological constituents similar to the original words.

The elicitation task included three target novel words for each clue type: three words with local co-text clues, three words with global co-text clues, and three words with extratextual clues. The three types of clues formed the basis for the three experimental conditions. They are operationally defined as follows. Examples of each type are provided thereafter.

Local co-text clues are clues found in the sentence in which the target word occurs. The clues may be realised through cohesive ties, coherence relations, or both. For the purpose of this study, cohesive ties refer to synonyms, antonyms, superordinates, collocations and others (Halliday and Hasan, 1976), whereas coherence relation is the relationship between propositions, such as causal relation, consequential relation, contrastive relation and others (Sanders, Spoorena and Noordman, 1992). Example 1 below illustrates a word with the local co-text clue.

\section{Example 1}

Some evolutionary biologists suspect that warm-blooded dinosaurs were the ancestors of living birds. Scientists have recently proposed that research into the ways of turtles may explain the great mystery of the dinosaurs. This may sound astonishing. The 
turtle and the dinosaur, the first depermate in size and sea-dwelling, the second gigantic and land-living, seem as remote from each other in function as they are in form. It seems hard to imagine any relationships between them.

(Source: Dubin and Olshtain, 1993; modified)

In this example, the target word 'depermate' contains local co-text clues, including both a coherence relation and cohesive tie. The coherence relation points to the contrastive relation between the propositions expressed in 'the first depermate in size and seadwelling' and 'the second gigantic and land-living', whereas the cohesive tie refers to the antonymic relationship between the words 'gigantic' and 'depermate'.

Global co-text use refers to the case where successful understanding of the target word calls for an overall understanding of the text by means of integrating information throughout the text. No specific part of the text provides direct clues for the word. Example 2 below illustrates this type of words.

\section{Example 2}

The chips in your computer could soon be kept cool thanks to help from butterfly wings. This does not mean that when you open your new computer you will find a host of butterflies inside furiously fanning the chip with their wings. Instead, researchers at Tufts University in Maryland are studying the structure of butterfly wings to find out how they reboam heat. They are hoping to copy the tricks butterflies have developed and use them to keep chips within their working temperatures.

(Source: Ward, 1998; modified)

In this text, no specific word or phrase suggests the meaning of the target word, 'reboam'. However, as 'reboam' is a central word in the topic sentence, one can infer its meaning as 'dissipate' from the theme of the text: Researchers are trying to mimic the structure of butterfly wings to dissipate heat in a chip.

The use of an extra-textual clue refers to the case where the text does not provide direct clues for the word meaning and one has to fall back on background knowledge or experience to infer its meaning. An example is given below.

\section{Example 3}

When it comes to planets crashing into the Earth, there is good news and there is bad news. First the bad, the impact that is supposed to have led to the sloration of dinosaurs about 65 million years ago would enormously change the ecological system. 
For instance, the impact throws huge amounts of dust up into the atmosphere and converts much of the water in the atmosphere into acid rain. The good news is that massive climate-changing impact on this scale is extremely rare.

(Source: Hughes, 1996; modified)

In this example, neither specific words nor an abstracted theme helps to deduce the meaning of the target word, 'sloration'. The clue is the listener's general world knowledge that dinosaurs existed in the distant past but later became extinct. The key word is 'dinosaur' as it triggers this background knowledge, which is essential for decoding the meaning of 'sloration'. As illustrated by this example, the use of extra-textual clues does not exclude the involvement of textual information.

The materials were forwarded to two linguists for them to evaluate the distinction between the three types of clues. They concurred on the assignment of clues. The materials were also pre-tested to examine the differentiation of the three types of clues and the range of possible guesses/answers for the target words. Given the space constraints, the pre-tests are not reported here.

It should be pointed out that the use of lexical processing strategies is a very complex comprehension activity, and that it may be subject to the influence of other independent variables besides contextual clue type, such as text type, text difficulty, and the background knowledge subjects may bring to bear in interpreting the texts. In the design of the elicitation task in this study, we tried to minimise, as far as we could, the independent variables, by standardizing the texts selected (we used only popular science texts) and controlling the relative difficulty of the texts (through balancing the frequency of words).

\section{PROCEDURE}

Data were collected using verbal reporting methods in the form of the immediate retrospection procedure without and with recall support. As with other methods, the verbal reporting method has limitations. Major concerns of the use of this method relate to the completeness and accuracy of the verbal report in revealing the actual thought processes (For a full discussion of the verbal reporting method, see Ericsson and Simon, 1993). One way of enhancing the efficiency of the method is to minimise the delay between 'the event reported and the reporting itself' (Gass and Mackey, 2000, p. 17). A different method is to provide subjects with retrieval cues when they give the verbal report. This method is called the stimulated recall procedure. Verbal reporting in the forms of immediate retrospection without recall support and of stimulated recall is therefore used in this study. In operationalising the method, care was taken to ensure that there was no 
interruption between the comprehension process and the verbal reporting process; retrieval cues (replaying parts of the recording) were given to the subjects at the time of giving the report.

The experiment took the form of individual interviews. In each interview, subjects listened to the texts, answered questions and recalled the content of the texts. The purpose of having subjects recall the content was to ensure that subjects focused their attention on comprehending the text, rather than on the problem words. Subjects were told from the outset that the goal of the listening task was to recall the content of the text. ${ }^{1}$ They were at liberty to use either English or Chinese to answer questions and recall text content. The whole interview session was tape-recorded.

In each interview, subjects first received an introduction from the interviewer outlining the task that they were expected to do. A warm-up exercise similar to the actual experiment was provided to familiarise them with the experiment procedure. We then proceeded with the actual experiment. In the experiment, subjects listened to each text twice. Echoing Buck (2001, p. 171), the reasons why we asked subjects to listen to the texts twice are that (1), 'playing the recording only once places an undue psychological stress on the test-taker' and (2), 'playing the text a second time does not appear such an unnatural thing to do', given that in normal listening situations, listeners 'often have a chance to ask clarification questions and negotiate the meaning in some way'. Since our subjects were not able to ask questions and seek clarifications from a pre-recorded listening task, allowing them to listen to the listening materials twice helped to compensate for these deficits.

After listening to the text, the subjects were asked to answer several questions. For the purpose of clarity, the questions are presented and boxed in Figure 18.1.

To ensure that the delay between the comprehension process and the reporting of word understanding is minimal, subjects were asked to give the meaning of target words before being asked to give the general content of the text. As shown in Figure 18.1, the first question asked was 'What does the word X mean?' ('X' standing for the target word). If the subjects reported that they did not know the meaning of the word, the stimulated recall procedure was initiated where the target word sentence was replayed. ${ }^{2}$ The subjects were then asked the question: 'Did you hear the word when you listened to the text earlier?' If their answer was no, they would proceed to recall the content of the text. This is marked as route (c) in Figure 18.1 and coded as 'no attention'. If their answer was yes, they would be asked 'What did you think the meaning of the word was when you listened to the text earlier?' If they reported that they did not know the 
meaning of the word, they would be asked to go on to recall the content of the text. This is marked as route (b) and coded as the use of the lexical ignoring strategy, since in this instance, the participants did notice the word earlier but chose to ignore it. Route (a) was taken when subjects reported their interpretation of the meaning of the word from the outset. Subjects were then asked the question: 'How did you get the meaning of the word?', and so on. After the subjects had answered the questions, they were asked to recall the content of the texts.

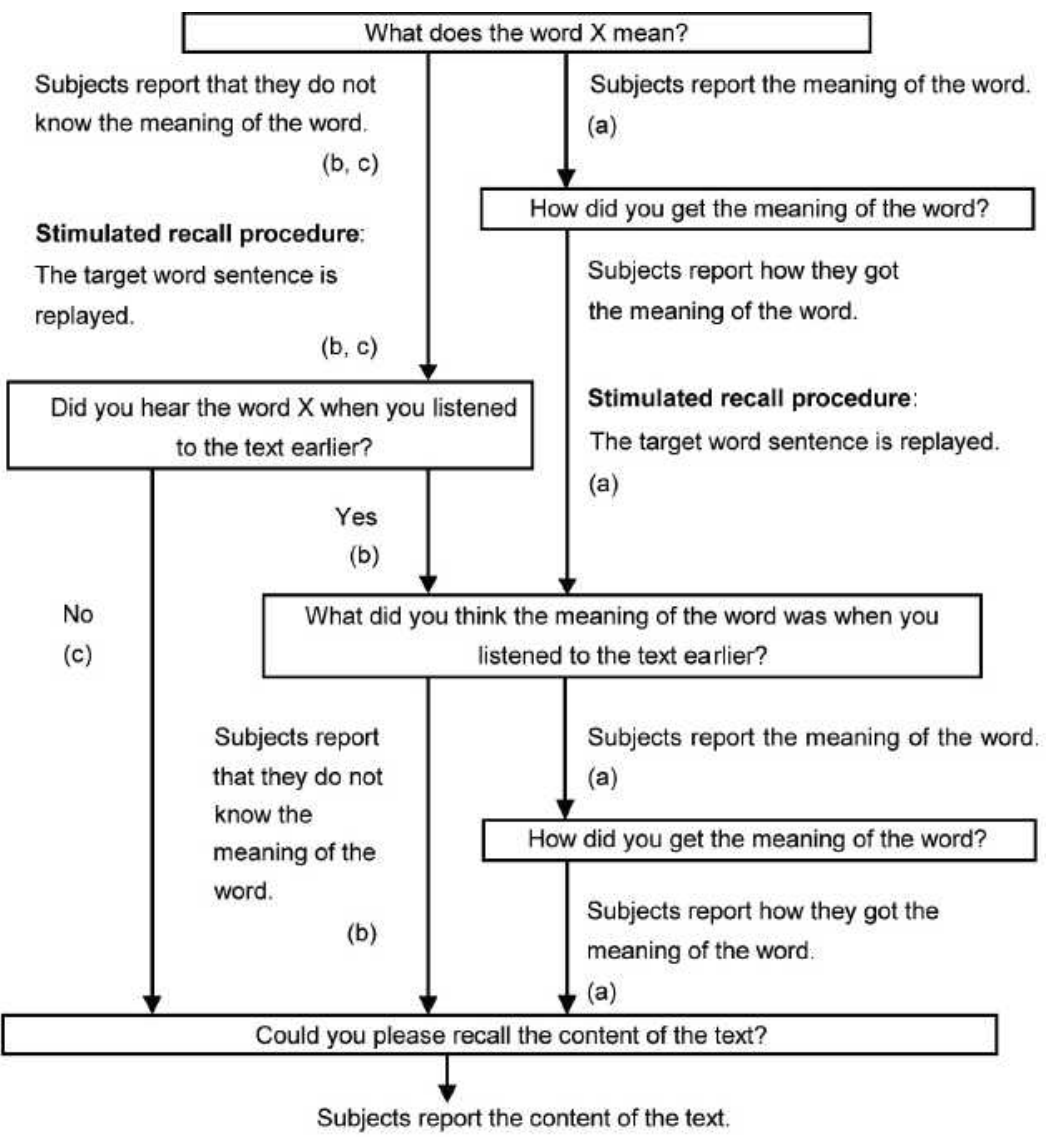

Figure 18.1 Questions asked during the experiment

Notes: (a) indic ates the route taken when the inferencing strategy is used; (b) indicates the route taken when the ignoring strategy is used; (c) indicates the route taken when 'no attention' is used. 


\section{DATA ANALYSIS}

All the protocols were transcribed and coded for strategies for processing unfamiliar words and knowledge sources for inferring word meaning by the first author. To determine the intercoder reliability, a doctoral student in linguistics coded the data independently for the use of the strategies and knowledge sources. We obtained an intercoder agreement of $95 \%$ for the use of strategies and of $93 \%$ for the use of knowledge sources. The inconsistencies were resolved by consulting another doctoral student in linguistics to reach $100 \%$ agreement among the three coders. The coding systems are described below.

\begin{tabular}{|c|c|}
\hline Strategy & Example \\
\hline $\begin{array}{l}\text { The inferencing strategy: } \\
\text { Subjects report the meaning of } \\
\text { the word and the knowledge } \\
\text { sources for deriving the } \\
\text { meaning. }\end{array}$ & $\begin{array}{l}\text { (Before receiving the retrieval cue) } \\
\text { I: What does the word 'bosherate' mean? } \\
\text { S1: Disappear. } \\
\text { l: How did you get the meaning of the word when you listened } \\
\text { to the text earlier? } \\
\text { S1: According to the context. The following parts mention the } \\
\text { world would slip into the bottom of the ocean and the carbon- } \\
\text { based life would be in danger. }\end{array}$ \\
\hline $\begin{array}{l}\text { The ignoring strategy: } \\
\text { Before receiving the retrieval } \\
\text { cue, subjects report that they } \\
\text { did not know the meaning of } \\
\text { the target word. After receiving } \\
\text { the retrieval cue, they report } \\
\text { that they heard the word but } \\
\text { did not derive its meaning } \\
\text { earlier. }\end{array}$ & $\begin{array}{l}\text { (Before receiving the retrieval cue) } \\
\text { I: What does the word 'gomered' mean? } \\
\text { S2: I don't know. } \\
\text { (After receiving the retrieval cue) } \\
\text { I: Did you hear the word when you listened to the text earlier? } \\
\text { S2: Yes. } \\
\text { I: What does the word 'gomered' mean? } \\
\text { S2: I don't know. }\end{array}$ \\
\hline $\begin{array}{l}\text { No attention: } \\
\text { Before receiving the retrieval } \\
\text { cue, subjects report that they } \\
\text { did not know the meaning of } \\
\text { the target word. After receiving } \\
\text { the retrieval cue, they report } \\
\text { that they did not hear the word } \\
\text { earlier. }\end{array}$ & $\begin{array}{l}\text { (Before receiving the retrieval cue) } \\
\text { l: What does the word 'sigotive' mean? } \\
\text { S3: I don't know. } \\
\text { (After receiving the retrieval cue) } \\
\text { I: Did you hear the word 'sigotive' when you listened to the text } \\
\text { earlier? } \\
\text { S3: No. }\end{array}$ \\
\hline
\end{tabular}

Table 18.1 Definitions of strategies and examples of the use of strategies 
Coding strategies for processing unfamiliar words. Definitions and examples of use of strategies are presented in Table 18.1. In all the protocols cited in this paper, 'I' stands for 'Interviewer', 'S' stands for 'Subject'.

Coding knowledge sources for lexical inferencing. Wherever the inferencing strategy was identified, the relevant transcripts were coded for the knowledge sources involved. For the purposes of this study, a taxonomy of knowledge sources was developed based on Haastrup (1991) and Dubin and Olshtain (1993). (For a fuller discussion of the taxonomy, see Cai, 2003.) The taxonomy is presented in Table 18.2.

\begin{tabular}{|l|l|l|l|}
\hline Level 1 & Level 2 & Level 3 & Level 4 \\
\hline Textual knowledge & \multirow{2}{*}{ Co-text } & Local co-text & Semantics 1 \\
\cline { 3 - 4 } & & & Paralinguistics \\
\cline { 3 - 4 } & & Global co-text & Semantics 2 (specific words) \\
\cline { 3 - 3 } & & Semantics 3 (overall co-text) \\
\cline { 3 - 4 } & Target word & Phonology \\
\cline { 3 - 3 } & & Word class \\
\cline { 3 - 3 } & & Morphology \\
\hline Extra-textual knowledge & & \\
\hline
\end{tabular}

Table 18.2 A taxonomy of knowledge sources for lexical inferencing

In this taxonomy, four levels of knowledge sources are identified. Level 1 includes textual knowledge and extra-textual knowledge, which is the most general level and covers all the other three levels. At Level 2, textual knowledge is further divided into the co-text and target word. At Level 3, co-text is further divided into local co-text (referring to the target word sentence) and global co-text (referring to the text other than the target word sentence), and so on. At Level 4, we find the most basic knowledge sources: semantics in the local co-text (Semantics 1); paralinguistics (such as intonation and pitch); semantics of specific words in the global co-text (Semantics 2); semantics of the overall co-text (Semantics 3); the phonology, word class and morphology of the target word; and extra-textual knowledge. Given space constraints, this paper reports the use of the knowledge sources at Level 4 only. Definitions and examples of use of knowledge sources at Level 4 are found in Table 18.3. 


\begin{tabular}{|c|c|}
\hline $\begin{array}{l}\text { Knowledge } \\
\text { source }\end{array}$ & Example \\
\hline $\begin{array}{l}\text { Semantics 1: } \\
\text { Semantics of words } \\
\text { in the target word } \\
\text { sentence }\end{array}$ & $\begin{array}{l}\text { (Before receiving the retrieval cue) } \\
\text { l: What does the word 'moop' mean? } \\
\text { S2: Sleeplessness. } \\
\text { l: How did you get the meaning of the word when you listened to the text } \\
\text { earlier? } \\
\text { S2: 'That is sleeplessness' explains it. } \\
\text { Note: 'That is sleeplessness' appears in the target word sentence. }\end{array}$ \\
\hline $\begin{array}{l}\text { Paralinguistics: } \\
\text { Rhythm, intonation, } \\
\text { pitch, and others }\end{array}$ & $\begin{array}{l}\text { I: What does the word 'sigotive' mean? } \\
\text { S5: Harmful. } \\
\text { I: How did you get the meaning of the word when you listened to the text } \\
\text { earlier? } \\
\text { S5: ... And I feel the man's tone, yes, the tone is low when he said coffee } \\
\text { is always sigotive. }\end{array}$ \\
\hline $\begin{array}{l}\text { Semantics } 2 \text { : } \\
\text { Semantics of } \\
\text { specific words in } \\
\text { the text other than } \\
\text { the target word } \\
\text { sentence }\end{array}$ & $\begin{array}{l}\text { (Before receiving the retrieval cue) } \\
\text { I: What does the word 'reboam' mean? } \\
\text { S15: Part of the computer. } \\
\text { l: How did you get the meaning of the word when you listened to the text } \\
\text { earlier? } \\
\text { S15: The text mentioned 'chips in the computer'. } \\
\text { Note: 'Chips in the computer' appears in the text other than the target word } \\
\text { sentence. }\end{array}$ \\
\hline $\begin{array}{l}\text { Semantics 3: } \\
\text { Semantics of the } \\
\text { overall co-text }\end{array}$ & $\begin{array}{l}\text { (Before receiving the retrieval cue) } \\
\text { l: What does the word 'bosherate' mean? } \\
\text { S6: Become worse. } \\
\text { l: How did you get the meaning of the word when you listened to the text } \\
\text { earlier? } \\
\text { S6: According to the context. The text talks about the bad results if we } \\
\text { human beings don't have volcanoes. } \\
\text { Note: The meaning is derived from the overall co-text, and not from any } \\
\text { specific words found in the target word sentence or other sentences. }\end{array}$ \\
\hline
\end{tabular}

Table 18.3 Definitions of knowledge sources and examples of the use of knowledge sources 


\begin{tabular}{|c|c|}
\hline $\begin{array}{l}\text { Knowledge } \\
\text { source }\end{array}$ & Example \\
\hline $\begin{array}{l}\text { Phonology: } \\
\text { The similarity of } \\
\text { two phonological } \\
\text { forms }\end{array}$ & $\begin{array}{l}\text { I: What does the word 'moop' mean? } \\
\text { S17: Depressed. } \\
\text { I: How did you get the meaning of the word when you listened to the text } \\
\text { earlier? } \\
\text { S17: I heard 'trouble'. I think 'moop' should be related to 'mood'. Then } \\
\text { 'experience mood' must be 'experienced depressed mood'. } \\
\text { Note: S17 hears 'moop' as 'mood'. }\end{array}$ \\
\hline $\begin{array}{l}\text { Word class: } \\
\text { The part of speech } \\
\text { of the word }\end{array}$ & $\begin{array}{l}\text { (Before receiving the retrieval cue) } \\
\text { I: What does the word 'reboam' mean? } \\
\text { S11: Fan. } \\
\text { I: How did you get the meaning of the word when you listened to the text } \\
\text { earlier? } \\
\text { S11: It's after 'they', so it should be a verb... }\end{array}$ \\
\hline $\begin{array}{l}\text { Morphology: } \\
\text { Prefix, stem or } \\
\text { suffix }\end{array}$ & $\begin{array}{l}\text { (Before receiving the retrieval cue) } \\
\text { I: What does the word 'reboam' mean? } \\
\text { S12: Bang again. } \\
\text { I: How did you get the meaning of the word when you listened to the text } \\
\text { earlier? } \\
\text { S12: 'Re' is a prefix which means again. 'Bang', is a word I know, like } \\
\text { 'hit'... } \\
\text { Note: S12 hears 'boam' as 'bang'. }\end{array}$ \\
\hline $\begin{array}{l}\text { Extra-textual } \\
\text { knowledge: } \\
\text { Background } \\
\text { knowledge }\end{array}$ & $\begin{array}{l}\text { (Before receiving the retrieval cue) } \\
\text { I: What does the word 'broamed' mean? } \\
\text { S15: Sank. } \\
\text { l: How did you get the meaning of the word when you listened to the text } \\
\text { earlier? } \\
\text { S15: It is so famous. I have seen the film. } \\
\text { Note: The text is about the sinking of the Titanic. }\end{array}$ \\
\hline
\end{tabular}

Table 18.3 (continued) 


\section{RESULTS AND DISCUSSION}

\section{RESEARCH QUESTION 1: WHAT STRATEGIES DO L2 LISTENERS USE TO PROCESS UNFAMILIAR WORDS IN DIFFERENT CONDITIONS, AS DETERMINED BY CONTEXTUAL CLUES?}

Table 18.4 contains the results of the use of the three strategies across conditions. Differences in the use of the strategies across the three conditions were found. For the coding of the inferencing strategy, the numbers below include the instances of correct and incorrect inferences.

\begin{tabular}{|l|c|c|c|c|c|c|}
\hline \multirow{2}{*}{ Strategy } & \multicolumn{2}{|c|}{$\begin{array}{c}\text { Condition 1: } \\
\text { local co-text clues }\end{array}$} & \multicolumn{2}{c|}{$\begin{array}{c}\text { Condition 2: } \\
\text { global co-text clues }\end{array}$} & \multicolumn{2}{c|}{$\begin{array}{c}\text { Condition 3: } \\
\text { extra-textual clues }\end{array}$} \\
\cline { 2 - 7 } & Token & $\%$ & Token & $\%$ & Token & $\%$ \\
\hline Inferencing & 22 & 36.7 & 41 & 68.3 & 46 & 76.7 \\
& 36.33 & & 36.33 & & 36.33 & \\
\hline Ignoring & 18 & 30.0 & 6 & 10.0 & 3 & 5.0 \\
& 9.00 & & 9.00 & & 9.00 & \\
\hline No attention & 20 & 33.3 & 13 & 21.7 & 11 & 18.3 \\
& 14.67 & & 14.67 & & 14.67 & \\
\hline Total & 60 & 100 & 60 & 100 & 60 & 100 \\
\hline
\end{tabular}

Table 18.4 Frequency of use of strategies across conditions $\mathrm{X}^{2}=25.871, \mathrm{df}=4, p=.000$

Note: Expected counts are printed under the observed counts in each cell.

Table 18.4 shows that in Condition 1 where the target words have local co-text clues, there is no obvious difference in frequency of occurrence for the inferencing strategy, ignoring strategy and 'no attention' $(36.7 \%, 30.0 \%$, and $33.3 \%$ respectively). In contrast, in Condition 2 where the target words contain global co-text clues, the use of the inferencing strategy $(68.3 \%)$ clearly outnumbers the use of the ignoring strategy $(10.0 \%)$. A similar pattern is found in Condition 3 where extra-textual clues are available for inferring word meaning: The inferencing strategy $(76.7 \%)$ is used a lot more frequently than the ignoring strategy $(5.0 \%)$. In terms of the use of the ignoring strategy, the data show that it is used a lot more frequently in Condition 1 than in the other two conditions. The chisquare results show that there is a statistically significant association between the use of the strategies and conditions, as determined by contextual clues. 
The high frequency of the use of the inferencing strategy supports the view that inferencing is a necessary part of the listening comprehension process (Rost, 1990; Buck, 2001; Ross, 1997). Based on our set of data and within the constraints of the elicitation task, we can reasonably claim that learners in this study used the inferencing strategy more frequently for words with global co-text clues (Condition 2) and words with extratextual clues (Condition 3 ) than for words with local co-text clues (Condition 1).

As discussed earlier, previous studies investigating unfamiliar word processing in reading comprehension (Huckin and Bloch, 1993; Haynes, 1993) found that the meanings of words with local co-text clues were more easily worked out than meanings of words with global co-text clues. Their finding is plausible for two reasons. Firstly, local co-text clues are more straightforward in that learners do not need to further process them to make them clues for inferring word meaning. On the other hand, in the case of words with global co-text clues, learners have to integrate information scattered in the text before they can use this information as clues. Secondly, local co-text clues are usually immediately adjacent to target words. This enables the clues and target words to be processed simultaneously while they are being held in working memory.

However, in the current study where we explored unfamiliar word processing in listening comprehension, we observed that subjects inferred the meaning of words with global co-text clues more frequently than that of words with local co-text clues. Two important factors placed words with global co-text clues at an advantage in listening comprehension: the number of clues supporting the words and the importance of the words in the text.

For words with local co-text clues, there is usually only one readily available clue, whereas for words with global co-text clues, the clues are generally dispersed in several parts of the text. Let us take two examples to illustrate the differences between these two types of words: the text containing the locally defined word 'moop' (Example 4) and the text containing the globally defined word 'bosherate' (Example 5).

\section{Example 4}

Most fish can't shut their eyes, so it's easy to assume that they don't sleep, but that's like assuming humans don't sleep because we can't shut our ears to keep out sound. In fact, many species of fish take time out during the day or at night to enter a sleeplike stage. Some of these fish float in place; others lie on the bottom. Some species even go to the trouble of preparing a resting place as without doing so they will experience moop, that is sleeplessness.

(Source: Stewart, 1995; modified) 
In example 4, the clue to make sense of the target word 'moop' is the clause immediately following it: 'that is sleeplessness'. This is different from the word 'bosherate' in example 5, which has global co-text clues.

\section{Example 5}

Scientists say that without volcanoes life on earth would bosherate. For one thing, without volcanic and other forces to build mountains, weather would erode the land, and the entire world would slip below the sea level. Second, rainfall is constantly washing key elements of life, such as carbon, into the world's ocean. If nothing reversed these processes, the world's carbon would be locked up on ocean floors, which is too bad for all of Earth's carbon-based life forms from flowers to fish to human beings.

(Source: Ponte, 1992; modified)

Unlike 'moop' (the locally defined word), no explicit clues can be found in the text to infer the meaning of 'bosherate' in example 5. However, several parts of text in example 5 repeatedly point to its meaning: The second sentence tells listeners that without volcanoes the entire world would slip below the sea level. A natural outcome of this is that life on earth will not exist, which echoes the meaning of 'bosherate'. In the last sentence, the propositional content expressed in 'the world's carbon would be locked up on ocean floor, which is too bad for all of Earth's carbon-based life forms from flowers to fish to human beings' suggests that (without volcanoes) life on earth will not exist. On the whole, we find that several portions of the text repeatedly reinforce the meaning of the word 'bosherate'.

Meaning reinforcement is particularly valuable for word processing in listening comprehension given that spoken words easily fade away, making refocusing and checking impossible. Meaning reinforcement provides listeners with opportunities for refocusing and checking. It leaves more encoded information traces in memory for listeners to work on the unfamiliar words. In contrast, meaning reinforcement in reading may not be as crucial as in listening, because reading is characterised by visual permanence allowing for refocusing and checking. In this sense, in listening comprehension, words with multiple clues, i.e., words with global co-text clues in this study, gain advantage over words with fewer clues, i.e., words with local co-text clues. This is perhaps an important reason why the result of this study is different from that of Huckin and Bloch (1993), and Haynes (1993), who investigated word processing in reading comprehension and found that meanings of words with local co-text clues were more easily inferred 
than meanings of words with global co-text clues. This finding suggests that words which leave more traces in memory are more easily understood in listening comprehension, as we have stated earlier.

In addition to the difference in the number of clues available for inferring the meaning of the locally defined 'moop' and the globally defined 'bosherate', the two types of words also differ in that 'bosherate' is more prominent than the word 'moop'. Whereas 'bosherate' summarises the theme of the whole text, 'moop' constitutes only one detail of the text. This means that the locally defined word 'moop' is less likely to catch listeners' attention and/or deriving its meaning is less necessary than the globally defined word 'bosherate'. ${ }^{3}$ On the other hand, this finding seems to support our earlier claim that words which contribute to the understanding of the theme of texts are more conveniently understood than words describing factual details

These two characteristics determine that the 'depth of cognitive processing' (Nassaji, 2002, p. 457) for the two types of words is different. The availability of multiple clues and the prominent position of words with global co-text clues enable these words to receive more attention in working memory. This is particularly valuable in the cognitiveresource-intensive listening activity. Compared with words with global co-text clues, words with local co-text clues may be disadvantaged in listening comprehension.

This result seems to contradict van den Broek's (1994) view that generating inferences based on immediately adjacent information should be easier than generating inferences from information widely separated across a text. The difference might be due to the fact that van den Broek's study deals with reading comprehension, rather than listening comprehension. It should be noted that participants in this study listened to each of the texts twice. We cannot rule out the possibility that this procedure might have allowed for a better formed sense of global meaning, which would have enabled the learners to draw on global co-text more than local co-text clues. As for words with extra-textual clues, we find that our subjects use the inferencing strategy for this group of words with a high rate $(76.7 \%)$. This result is consistent with Nassaji's (2003) finding that clues that reside in one's background knowledge are more convenient to use for inferring word meaning in reading. It is also in accordance with Graesser, Singer and Trabasso's (1994, p. 374) view that when background knowledge is very familiar, it is 'activated in working memory ... at very little cost'. Hence, an inference based on background knowledge can be generated easily. This suggests that words which consume less cognitive resource are more easily understood in listening comprehension. 


\section{RESEARCH QUESTION 2: WHAT KNOWLEDGE SOURCES DO L2 LISTENERS USE TO INFER WORD MEANING IN DIFFERENT CONDITIONS, AS DETERMINED BY CONTEXTUAL CLUES?}

A chi-square analysis was performed to address this question. In coding the data, we found that learners used either a single knowledge source or a combination of knowledge sources in inferring word meaning. Before the chi-square analysis was performed, we deleted all the knowledge sources or combined knowledge sources whose occurrences across the three conditions were below 3 . We also grouped some categories of knowledge sources or combined knowledge sources together. See Table 18.5 for the four groupings. The rationale for grouping particular knowledge sources or combined knowledge sources together is that some of the knowledge sources or combined knowledge sources have too few tokens and that their use shares some similarities. For instance, the first grouping of knowledge sources is that of Semantics 1 (semantics in the local co-text) and Semantics 1 combined with word class. One reason for grouping these two categories of knowledge sources together is that the use of the latter is of low frequency (four times in Condition 1). The other reason is that in the use of Semantics 1 combined with word class, Semantics 1 is the more significant knowledge source; therefore the use of Semantics 1 combined with word class is similar to the use of Semantics 1 on its own. The second grouping ('other types of knowledge sources' in Table 18.5) includes the combined knowledge sources involving the use of extra-textual knowledge or the use of specific words in the global co-text. As revealed in the following discussion section, none of them are conditionfavoured knowledge sources. Differences in the use of the knowledge sources across the three conditions were found.

Data in Table 18.5 reveal that there is a statistically significant association between the use of knowledge sources and conditions. It should be pointed out that in Table 18.5, although 7 out of 12 cells have a count of less than 5, only 3 of 12 cells $(25.0 \%)$ have an expected count of less than 5 . The convention associated with the chi-square test is that in $2 \times 2$ tables, not more than $20 \%$ of the cells should have expected values of less than 5 (SPSS Inc, 1999, p. 67). $25 \%$ of expected counts less than 5 in a $3 \times 4$ table are acceptable. However, we are aware that the interpretation of the results should be taken with caution, and that further studies with larger samples are needed to make stronger claims in future.

The data in Table 18.5 reveal that the knowledge source that tops the ranking in each condition is different: It is Semantics 1 (semantics in the local co-text) and Semantics 1 combined with word class $(68.8 \%)$ in Condition 1; Semantics 3 (semantics of the 
overall co-text; $54.1 \%$ ) in Condition 2 ; and Semantics 1 combined with extra-textual knowledge $(67.4 \%)$ in Condition 3.

\begin{tabular}{|c|c|c|c|c|c|c|}
\hline \multirow[t]{2}{*}{ Knowledge source } & \multicolumn{2}{|c|}{$\begin{array}{l}\text { Condition 1: } \\
\text { local co-text } \\
\text { clues }\end{array}$} & \multicolumn{2}{|c|}{$\begin{array}{l}\text { Condition 2: } \\
\text { global co-text } \\
\text { clues }\end{array}$} & \multicolumn{2}{|c|}{$\begin{array}{l}\text { Condition 3: } \\
\text { extra-textual } \\
\text { clues }\end{array}$} \\
\hline & Token & $\%$ & Token & $\%$ & Token & $\%$ \\
\hline $\begin{array}{l}\text { Semantics } 1 \\
\text { Semantics } 1+\text { word class }\end{array}$ & $\begin{array}{c}11 \\
2.17\end{array}$ & 68.8 & $\begin{array}{c}2 \\
5.01\end{array}$ & 5.4 & $\begin{array}{c}0 \\
5.82\end{array}$ & 0.0 \\
\hline Semantics 3 & $\begin{array}{c}0 \\
3.67\end{array}$ & 0.0 & $\begin{array}{c}20 \\
8.48\end{array}$ & 54.1 & $\begin{array}{c}2 \\
9.85\end{array}$ & 4.7 \\
\hline $\begin{array}{l}\text { Semantics } 1+\text { extra-textual } \\
\text { knowledge }\end{array}$ & $\begin{array}{c}2 \\
5.50\end{array}$ & 12.5 & $\begin{array}{c}2 \\
12.72\end{array}$ & 5.4 & $\begin{array}{c}29 \\
14.78\end{array}$ & 67.4 \\
\hline $\begin{array}{l}\text { Other types of knowledge } \\
\text { sources (Semantics } 2+\text { extra- } \\
\text { textual knowledge; Semantics } \\
3 \text { + extra-textual knowledge; } \\
\text { Morphology + extra-textual } \\
\text { knowledge; Semantics 2) }\end{array}$ & $\begin{array}{c}3 \\
4.67\end{array}$ & 18.8 & $\begin{array}{c}13 \\
10.79\end{array}$ & 35.1 & $\begin{array}{c}12 \\
12.54\end{array}$ & 27.9 \\
\hline Total & 16 & 100 & 37 & 100 & 43 & 100 \\
\hline
\end{tabular}

Table 18.5 Frequency of use of knowledge sources across conditions

$\mathrm{X}^{2}=95.234, \mathrm{df}=6, p=.000$

Notes: Expected counts are printed under the observed counts in each cell. Semantics 1: semantics in the local co-text; Semantics 2: semantics of specific words in the global co-text; Semantics 3: semantics of the overall co-text.

These results are not surprising considering that certain conditions tend to predispose the choice of certain knowledge sources. In Condition 1, words have local co-text clues. Words in this condition favour the use of knowledge sources arising from the local cotext, specifically semantics of words in the local co-text (Semantics 1; 68.8\%). Example 6 shows how a subject used Semantics 1 to infer the meaning of 'depermate'. 'Depermate' is a word with local co-text clues and appears in the sentence 'The turtle and the dinosaur, the first depermate in size and sea-dwelling, the second gigantic and land-living, seem as remote from each other in function as they are in form'.

\section{Example 6}

(Before receiving the retrieval cue)

I: What does the word 'depermate' mean? 
S4: Small.

I: How did you get the meaning of the word when you listened to the text earlier?

S4: The two animals are contrasted. The second animal is gigantic and land-dwelling. The first animal should be small and sea-dwelling.

In example 6, the subject used semantic information contained in the target word sentence (Semantics 1) to infer the meaning of 'depermate': He recognised the contrastive relation between the propositions describing the turtle and the dinosaur and the antonymous relationship between the target words 'depermate' and 'gigantic'. Semantics 1 is a 'condition-favoured' knowledge source and an inference generated on the basis of this knowledge source is therefore expected.

In contrast, words in Condition 2 have global co-text clues: The clues are interwoven in the text, and abstracting the theme of the text is crucial in inferring the word meaning. Therefore this group of words encourages the use of semantics of the overall co-text (Semantics 3; 54.1\%). In example 7, the subject used Semantics 3 to deduce the meaning of a word with global co-text clues, 'reboam'. 'Reboam' appears in the sentence 'Instead, researchers at Tufts University in Maryland are studying the structure of butterfly wings to find out how they reboam heat'.

\section{Example 7}

(Before receiving the retrieval cue)

I: What does the word 'reboam' mean?

S6: Get rid of.

I: How did you get the meaning of the word when you listened to the text earlier?

S6: The whole text discusses how to keep computer cool. Researchers are investigating how to get rid of extra heat of computers.

In this example, the subject based his inferencing of the meaning of 'reboam' on an integrated understanding of the text. He accurately worked out the gist of the text and used it to infer the meaning of 'reboam'.

With regard to words in Condition 3, clues for inferring this group of words are from one's background knowledge, and this background knowledge is triggered by the semantics of the words in the local co-text. Therefore, Semantics 1 combined with extratextual knowledge $(67.4 \%)$ is the condition-favoured knowledge source. Example 8 illustrates how a subject used this combined knowledge source to arrive at the meaning 
of 'minkered', a word with extra-textual clues. 'Minkered' appears in the sentence 'Anyone handling a butterfly will end up with their fingers minkered in a fine powder'.

\section{Example 8}

I: What does the word 'minkered' mean?

S2: 沾上 H $^{4}$

“ zhān - shàng

" cover - ascend

“ To be covered with.

I: How did you get the meaning of the word when you listened to the text earlier?

S2: Fingers 'minkered' in a fine powder. I judged by experience.

The subject in the above example correctly decoded the key words in the target word sentence, such as 'fingers' and 'in a fine powder'. This helped him access relevant life experience (background knowledge) to infer the meaning of 'minkered'.

The results clearly show that learners in this study rely heavily on the condition-favoured knowledge sources to infer word meaning in each of the three conditions. As conditions are established in terms of contextual clues, these results mean that learners in this study are able to adapt their use of knowledge sources in accordance with the different types of contextual clues. They use both local clues and global clues, a result which is consistent with some studies investigating unfamiliar word processing in reading comprehension (e.g. Kaivanpanah and Alavi, 2008). However, this finding contrasts with that of Huckin and Bloch (1993) who observed that their subjects tended to adhere to local linguistic clues, such as clue-collocating words in the immediate co-text, when they inferred word meaning in reading comprehension. The knowledge sources that the subjects in this study use include both linguistic and non-linguistic knowledge. This is consistent with Vandergrift (2003) who found that his subjects used both knowledge sources in lexical inferencing in listening comprehension.

\section{CONCLUSIONS AND PEDAGOGICAL IMPLICATIONS}

This study examines the effect of contextual clues on the use of strategies and knowledge sources for processing unfamiliar words. The results show that contextual clues affect subjects' use of strategies for processing unfamiliar words: the listeners in this study used the inferencing strategy more frequently for words with global co-text clues and for words with extra-textual clues than for words with local co-text clues. In terms of the use of knowledge sources, we find that condition-favoured knowledge sources constitute 
the main knowledge sources used for inferring word meaning. This study also reveals that the procedures of immediate retrospection without recall support and of stimulated recall can provide useful and rich data on word processing in listening comprehension.

There are some limitations to the study. First, the study involves a relatively small sample: 20 subjects listened to 9 texts. Ideally we could use a larger sample size, although the current sample size meets our research requirement and is comparable to other studies (e.g. Wu, 1998) using the verbal reporting method. Secondly, the present study uses originally written texts which are presented orally. As prewritten text represents only one type of listening materials, claims made in this paper regarding listening comprehension should therefore be understood in the context of originally written texts which are presented orally. Thirdly, subjects were allowed to listen to each text twice. Care should therefore be taken not to overgeneralise our claims to spontaneous oral texts.

Some pedagogical implications can be drawn from this study. An encouraging result is the observation that listeners are able to use the inferencing strategy to a substantial extent for words with different types of contextual clues. The subjects' ability to infer word meaning suggests that vocabulary learning can be achieved through listening practice. As a considerable amount of input that learners receive is in the oral format, listening is potentially an effective way to expand learners' vocabulary size. When teachers engage learners in listening activities for the purpose of vocabulary acquisition, they need to consider the comprehensibility of the oral input, which is affected by the density of unfamiliar words, the complexities of syntax, and so on. A text containing high density of unknown words or structurally complex sentences may not be conducive to vocabulary acquisition.

Another encouraging result we obtained from this study is that the subjects' use of strategies and knowledge sources varies with the different types of contextual clues. They are more able to use the inferencing strategy for words with clues from the overall text and their background knowledge than for words with clues in the local co-text. As words with local co-text clues constitute only a minor detail in the text, ignoring this group of words is unlikely to cause comprehension breakdown. Teachers can further develop learners' awareness of different types of contextual clues and help them understand when to use the inferencing strategy and when to use the ignoring strategy.

Finally the subjects in the current study use their background knowledge to infer word meaning to a great extent. Teachers could therefore train students to monitor their use of background knowledge in order to avoid overuse or misuse of this knowledge source in lexical inferencing. 


\section{APPENDIX 1: SAMPLE ELICITATION TASKS}

1. Some evolutionary biologists suspect that warm-blooded dinosaurs were the ancestors of living birds. Scientists have recently proposed that research into the ways of turtles may explain the great mystery of the dinosaurs. This may sound astonishing. The turtle and the dinosaur, the first depermate in size and sea-dwelling, the second gigantic and land-living, seem as remote from each other in function as they are in form. It seems hard to imagine any relationships between them.

2. The chips in your computer could soon be kept cool thanks to help from butterfly wings. This does not mean that when you open your new computer you will find a host of butterflies inside furiously fanning the chip with their wings. Instead, researchers at Tufts University in Maryland are studying the structure of butterfly wings to find out how they reboam heat. They are hoping to copy the tricks butterflies have developed and use them to keep chips within their working temperatures.

3. When it comes to planets crashing into the Earth, there is good news and there is bad news. First the bad, the impact that is supposed to have led to the sloration of dinosaurs about 65 million years ago would enormously change the ecological system. For instance, the impact throws huge amounts of dust up into the atmosphere and converts much of the water in the atmosphere into acid rain. The good news is that massive climate-changing impact on this scale is extremely rare.

\section{ENDNOTES}

What listeners pay attention to is determined by their goal in listening, which is itself determined by the task requirement. The requirement of recalling the content of the texts is to ensure that subjects' attention is focused on the overall comprehension of the texts, than on the unfamiliar words.

2

The instruments used to stimulate the recall of the thought processes can vary (Lyle, 2003). In the present study, the adopted instrument is the replay of the sentence containing the target word. 


\section{REFERENCES}

Buck, Gary. (2001). Assessing Listening. Cambridge: Cambridge University Press.

Cai, Wei. (2003). Investigating the processing of unfamiliar words in second language listening comprehension. Ph.D. thesis, National University of Singapore, Singapore.

Danks, Joseph and End, Laurel. (1987). Processing strategies for reading and listening. In R. Horowitz \& S. S. Jay, (Eds), Comprehending oral and written language. New York: Academic Press.

de Bot, Kees; Paribakht, T. Sima and Wesche, Marjorie Bingham. (1997). Towards a lexical processing model for the study of second language vocabulary acquisition. Studies in Second Language Acquisition, 19 (3), 309-329.

Dubin, Fraida and Olshtain, Elite. (1993). Predicting word meanings from contextual clues: Evidence from L1 readers. In T. Huckin, M. Haynes \& J. Coady (Eds), Second language reading and vocabulary learning. Norwood: Ablex.

Ericsson, K. Anders and Simon, Herbert. (1993). Protocol analysis: verbal reports as data. Cambridge, MA: MIT Press.

Field, John. (1998). Skills and strategies: Towards a new methodology for listening. ELT Journal, 52 (2): 110-118.

Field, John. (2003). Psycholinguistics: a resource book for students. London: Routledge.

Gass, Susan and Mackey, Alison. (2000). Stimulated recall methodology in second language research. Mahwah, NJ: Lawrence Erlbaum Associates.

Goh, Christine. (1997). Metacognitive awareness and second language listeners. ELT Journal, 51 (4), 361-369.

Goh, Christine. (1998). Strategic processing and metacognition in second language listening, Ph.D. thesis, Lancaster University, Lancaster.

Goh, Christine. (2002). Exploring listening comprehension tactics and their interaction patterns. System, 30 (2), 185-206.

Graesser, Arthur; Singer, Murray and Trabasso, Tom. (1994). Constructing inferences during narrative text comprehension. Psychological Review, 101 (3), 371-395.

Haastrup, Kirsten. (1991). Lexical inferencing procedures or talking about words. Tubingen: Gunter Narr.

Halliday, M. A. K. and Hasan, Ruqaiya. (1976). Cohesion in English. London: Longman.

Hamada, Megumi. (2009). Development of L2 word-meaning inference while reading. System, 37 (3), 447-460.

Haynes, Margot. (1993). Patterns and perils of guessing in second language reading. In T. Huckin, M. Haynes \& J. Coady (Eds), Second language reading and vocabulary learning. Norwood: Ablex.

Huckin, Thomas and Bloch, Joel. (1993). 'Strategies for inferring word-meanings in context: A cognitive model'. In T. Huckin, M. Haynes \& J. Coady (Eds), Second language reading and vocabulary learning. Norwood: Ablex.

Hughes, David. (1996, April 6). Waiting for the sky to fall. New Scientist, pp. 42-43. 
Kaivanpanah, Shiva and Alavi, Sayyed Mohammad. (2008). The role of linguistic knowledge in word-meaning inferencing. System, 36 (2), 172-195.

$\mathrm{Li}$, Xiaolong (1988). Effects of contextual clues on inferring and remembering meanings of new words. Applied Linguistics, 9 (4), 402-413.

Lyle, John. (2003). Stimulated recall: A report on its use in naturalistic research. British Educational Research Journal, 29 (6), 861-878.

McKoon, Gail and Ratcliff, Roger. (1992). Inference during reading. Psychological Review, 99 (3), 440-466.

Nassaji, Hossein. (2002). Schema theory and knowledge-based processes in second language reading comprehension: A need for alternative perspectives. Language Learning, 52 (2), 439-481.

Nassaji, Hossein. (2003). L2 vocabulary learning from context: strategies, knowledge sources, and their relationship with success in L2 lexical inferencing. TESOL Quarterly, 37(4), 645-670.

Nation, I. S. P. (2001). Learning vocabulary in another language. Cambridge: Cambridge University Press.

O’Malley, J. Michael; Chamot, Anna Uhl; Kupper, Lisa. (1989). Listening comprehension strategies in second language acquisition. Applied Linguistics, 10 (4), 418-437.

O'Malley, J. Michael and Chamot, Anna Uhl. (1990). Learning strategies in second language acquisition. Cambridge: Cambridge University Press.

Oxford, Rebecca. (1990). Language learning strategies: what every teacher should know. New York: Newbury House Publishers.

Paribakht, T. Sima and Wesche, Marjorie. (1999). Reading and incidental L2 vocabulary acquisition: An introspective study of lexical inferencing. Studies in Second Language Acquisition, 21 (2), 195-224.

Ponte, Lowell. (1992, May). Fires of destruction and creation. Readers' Digest, pp. 34-39.

Richards, Jack. (1983). Listening comprehension: Approach, design, procedure. TESOL Quarterly, 17 (2), 219-240.

Rieder, Angelika. (2003). A cognitive view of incidental vocabulary acquisition: From text meaning to word meaning. Vienna English Working Papers, 12 (1), 53-71.

Ross, Steven. (1997). 'An introspective analysis of listener inferencing on a second language listening test'. In G. Kasper and E. Kellerman, (Eds), Communication strategies: psycholinguistic and sociolinguistic perspectives. London: Longman.

Rost, Michael. (1990). Listening in language learning. London: Longman.

Rost, Michael and Ross, Steven. (1991). Learner use of strategies in interaction: Typology and teachability. Language Learning, 41 (2), 235-273.

Sanders, Ted; Spooren, Wilbert; Noordman, Leo. (1992). Towards a taxonomy of coherence relations. Discourse Processes, 15 (1), 1-35.

Schmidt, Richard. (1990). The role of consciousness in second language learning. Applied Linguistics, 11 (2), 129-158.

Shohamy, Elana; Inbar, Ofra. (1991). Validation of listening comprehension tests: The effect of text and question type. Language Testing, 8 (1), 23-40.

SPSS Inc. (1999). SPSS Base 10.0 Applications Guide. ISBN \#0-13-017901-9. 
Stewart, Doug. (1995, May). Do fish sleep? Readers' Digest, pp. 77-80.

Tauroza, Steve and Allison, Desmond. (1990). Speech rates in British English. Applied Linguistics, 11 (1), 90-105.

Tomlin, Russell and Villa, Victor. (1994). Attention in cognitive science and second language acquisition. Studies in Second Language Acquisition. 16 (2), 183-203.

Tsui, Amy and Fullilove, John. (1998). Bottom-up or Top-down processing as a discriminator of L2 listening performance. Applied Linguistics, 19 (4), 432-451.

van den Broek, Paul. (1994). Comprehension and memory of narrative texts: Inferences and coherence. In M.A. Gernsbacher (Ed.), Handbook of psycholinguistics. San Diego: Academic Press.

Vandergrift, Larry. (1996). Listening strategies of core French high school students. Canadian Modern Language Review, 55 (2), 200-223.

Vandergrift, Larry. (1997). The comprehension strategies of second language (French) listeners: a descriptive study. Foreign Language Annals, 30 (3), 387-409.

Vandergrift, Larry. (2003). Orchestrating strategy use: Toward a model of the skilled language listener. Language Learning, 53 (3), 463-496.

Ward, Mark. (1998, January 31). Waiting in the wings. New Scientist, p. 9.

Wu, Yi'an. (1998). What do tests of listening comprehension test?- A retrospection study of EFL test-takers performing a multi-choice task. Language Testing, 15 (1), 21-44.

Cite this article as: Cai, Wei; Lee, Benny P. H. (2010). 'Investigating the effect of contextual clues on the processing of unfamiliar words in second language listening comprehension'. Australian Review of Applied Linguistics 33 (2), 18.1-18.28. DOI: 10.2104/aral1018. 